\title{
MODERNIDADE, FUTURO E PROGRESSO EM ARTHUR RIMBAUD
}

\author{
Adalberto Luis VICENTE (UNESP/Araraquara)
}

\begin{abstract}
RESUMO: Tomando como referência a última parte de Une saison en enfer e, sobretudo, a "Segunda carta do vidente", endereçada a Paul Demeny, este artigo pretende discutir de que modo a poética de Rimbaud contribui para incluir nas discussões sobre a modernidade conceitos como o novo, o progresso e a crença no futuro, antecipando, assim, questões que serão fundamentais para compreender a modernidade do século XX.
\end{abstract}

PALAVRAS-CHAVE: Modernidade; Poesia francesa; Arthur Rimbaud.

\begin{abstract}
Taking as a reference the last part of Une saison en enfer, and especially, the "Second letter of the seer", addressed to Paul Demeny, this article intends to discuss how Rimbaud's poetry contributes to including, in discussions about modernity, concepts such as the new, progress, and the belief in the future, anticipating thus issues that will be fundamental to understanding the modernity of the twentieth century.
\end{abstract}

KEYWORS: Modernity; French poetry, Arthur Rimbaud.

Na segunda parte do epílogo, no entanto, o tom de fracasso ameniza-se. O poeta alude a uma "hora nova" e afirma "ter alcançado a vitória" para então anunciar uma das mais contundentes afirmações sobre a modernidade:

Sim, a hora nova é pelo menos severíssima.

Porque posso afirmar ter alcançado a vitória: o ranger de dentes, o silvar do fogo, os suspiros pestilentos se moderam. Todas as lembranças imundas se esvanecem. Meus últimos pesares se retiram - inveja dos mendigos, malfeitores, amigos da morte, retardados de todas as espécies. Danados, se eu me vingasse!

Sejamos absolutamente modernos.

Nada de cânticos: manter o terreno conquistado. Dura noite! O sangue seco esturrica no meu rosto, atrás de mim só tenho aquele horrendo arbusto!... (RIMBAUD, 1998, p. 191). 
Depois que Baudelaire introduziu o termo modernidade no horizonte literário do século XIX, dando-lhe o significado particular de conciliação do contingente e do eterno, nenhum outro poeta havia enfatizado tanto a necessidade de ser moderno. $\mathrm{O}$ contexto em que a afirmação aparece em "Adieu" marca, no entanto, uma postura diferente daquela do autor de Lesfleurs dumal. O fim de uma etapa de vida e de um projeto poético anunciados na parte anterior propicia uma "hora nova", um tempo novo em que o poeta alcança a vitória pelo esvanecimento de "todas as lembranças imundas". A necessidade de ser moderno é vista agora como a manutenção do "terreno conquistado". Expressões como "novo", "alcançar vitória" e, sobretudo, "manter o terreno conquistado" projetam a idéia de modernidade para a temporalidade futura: o presente agora se abre ao futuro e não mais se coloca em sua união com o eterno. $\mathrm{O}$ poeta pretende ser o primeiro dos novos videntes, aos quais virão suceder, no futuro, outros "horríveis trabalhadores", que "começarão pelos horizontes em que o outro [vidente] foi abatido" (RIMBAUD, 1980, p. 186), como afirma o poeta na Carta a Paul Demeny. A modernidade rimbaudiana afasta-se assim da visão pessimista que Baudelaire tinha do futuro e marca uma nova aliança com o tempo, que integrará o projeto de modernidade das vanguardas históricas. Com Rimbaud, o culto ao novo e a crença no futuro tornam-se componentes importantes do conceito de modernidade.

Dois anos antes de escrever "Adieu”, Rimbaud já havia anunciado seu projeto poético nas duas cartas conhecidas como Cartas do Vidente: a primeira, mais sintética, é destinada a GeorgesIzambard e está datada de 13 de maio de 1871. A segunda, endereçada Paul Demeny, foi escrita dois dias depois e constitui o texto mais importante para compreensão da poética rimbaudiana. Nessas Cartas, o poeta-adolescente delineia sua compreensão da relação entre tradição e inovação; entre presente, futuro e progresso. Encontramos, sobretudo na segunda Carta, alguns vocábulos que, a partir de então, vão compor o campo de discussão em torno da modernidade. Como lembra Antoine Compagnon no primeiro capítulo de $O s$ Cinco paradoxos da modernidade(2003), adentrar no conceito de modernidade é embrenhar-se em um labirinto de vocábulos que aparecem aos pares: "antigo e moderno, clássico e romântico, tradição e originalidade, rotina e novidade, imitação e inovação, evolução e revolução, decadência e progresso, etc" (p. 15). Pensar a modernidade parece ser assim um jogo de conceitos que, se não são necessariamente sinônimos, "formam um 
paradigma e se interpenetram" (COMPAGNON, 2003, p.15). As duas Cartas do Vidente são documentos significativos para se detectar o momento em que esse paradigma se estabelece nos moldes que tomará nas discussões sobre a modernidade no século XX.

O poeta apresenta a Segunda Carta como "uma hora de literatura nova" (RIMBAUD, 1980, p. 185) e inicia o texto com o poema "Chant de guerre parisien" ao qual atribui a qualificação de "salmo de atualidade" (RIMBAUD, 1980, p.185). O texto foi inspirado na Comuna de Paris, episódio que marcou profundamente o adolescente de Charleville e que elevou o tom crítico de sua poesia e a revolta que então impregnava seu espírito. Essa relação com o fato histórico demonstra o compromisso desta "literatura nova" com o presente, com os fatos do momento. Matei Calinescu(1991) afirma que o adjetivo e o substantivo "modernus" surgem na Baixa Idade Média, derivados de "modo", que significa recente, do agora. Embora ainda não haja uma oposição forte entre os termos, os "moderni" representavam os autores da atualidade, do presente, que pertenciam ao agora e que nele estavam imersos, em oposição aos "antiqui", termo que designava os autores do passado, no caso, os escritores gregos e os pais da Igreja (cf. CALINESCU, 1991, p. 23-25). O termo moderno preserva, de seus primeiros empregos, esse traço semântico de compromisso com o presente, e é neste sentido que Rimbaud nos apresenta o poema "Chant de guerre parisien" como exemplo de literatura nova e compromissada com o presente.

O poeta inicia então a Carta propriamente dita, que nos é apresentada como "prosa sobre o futuro da poesia" (RIMBAUD, 1980, p. 185). O texto constitui, portanto, um projeto de poesia futura. O momento é de um novo tempo para a poesia, que, aliada agora ao presente, pretende antecipar o futuro, ou seja, "buscar o novo no presente voltado para o futuro" (COMPAGNON, 2003, p. 38). Para o autor de Os Cinco Paradoxos da Modernidade (2003), essa postura distingue os primeiros modernos, “[...] que não acreditavam [...] no dogma do progresso, do desenvolvimento e da superação. Não depositavam sua confiança no tempo nem na história, onde não esperavam obter revanche." (p. 37), dos modernos da geração de 1870, entre os quais se destacam Rimbaud e Lautréamont. Estes dois poetas, embora atentos ao presente, projetam seu olhar para o futuro e para a coletividade. É natural, portanto, que manifestem a 
pretensão de fazer tábua rasa do passado, antecipando assim a militância das vanguardas históricas em sua pretensão antipassadista.

Nos parágrafos seguintes da Segunda Carta, Rimbaud exprime sua revolta contra a tradição e passa a pôr abaixo a "velharia poética", da poesia grega aos românticos. No entanto, é preciso atentar para argumento particular que o poeta utiliza para negar o passado: "se os velhos imbecis não tivessem encontrado apenas a significação falsa do Eu, não teríamos que varrer esses milhões de esqueletos que, há um tempo infinito, acumularam os produtos de sua inteligência caolha proclamando-se autores". (RIMBAUD, 1980, p. 196).

A diferença entre os "velhos imbecis" e o poeta moderno está, portanto, ancorada na significação do Eu. Para fazer-se vidente, o poeta deve antes conhecer a si mesmo, "ele procura sua alma, inspeciona-a, tenta-a, aprende-a" (p. 196) a fim de alcançar um sentido mais autêntico do Eu. Como já anunciara na Primeira Carta do Vidente por meio da célebre frase "Eu é um outro", Rimbaud considera o Eu como o repositório da imaginação, das sensações e das infinitas possibilidades do ser. A afirmação de que o eu é um outro, em sua complexa singeleza, tem gerado diversas leituras, sobretudo com a intenção de apreender a pluralidade da personalidade do poeta. Fala-se em dupla personalidade, consciência de um dualismo interno profundo, oposição entre o Rimbaud-menino, afável e bem comportado, mas oprimido pelos cuidados maternos, e oRimbaud-poeta, embriagado pela revolta e pelo desejo de liberdade. Guy Michaud e Hugo Friedrich, apoiados em certas passagens da Carta, lembram que a frase "eu é um outro" alude ao processo de criação e às manifestações do inconsciente. O poeta vidente não é mais subjugado pelas musas, mas pelas camadas coletivas profundas que o poeta chama de "alma universal". Esta se manifesta a partir de idéias que brotam das profundezas do Eu: "asssisto à eclosão do meu pensamento: eu a observo, eu a ouço: lanço uma flecha: a sinfonia revolve-se nas profundezas ou vem de um salto para a cena" (RIMBAUD, 1980, p. 186). É possível imaginar a fascinação que uma declaração dessa natureza causou nos surrealistas, que viram no texto das Cartas do Vidente uma primeira teorização da escrita automática e da livre associação. Para Rimbaud, portanto, a poesia é uma forma de conhecimento e para isso o criador necessita, antes de tudo, cultivar sua alma. E é preciso ser vidente, fazer-se vidente. Por 
um ato volitivo, o poeta atinge o "Inconnu". No entanto, há um método para se chegar a ele, o desregramento de todos os sentidos:

\begin{abstract}
O poeta se faz vidente por um longo, imenso, e racional desregramento de todos os sentidos. Todas as formas de amor, de sofrimento, de loucura, ele procura a si mesmo, ele esgota nele todos os venenos, para guardar apenas a quintessência. Inefável tortura na qual tem necessidade de toda fé, de toda força sobre-humana, onde ele se torna, entre todos, o grande doente, o grande criminoso, o grande maldito - e o Supremo Sábio! - Pois ele chegou ao Desconhecido. (RIMBAUD, 1980, p. 186).
\end{abstract}

Mesmo antes de aventurar-se em Paris - a partida só se efetivará quatro meses depois da escritura das Cartas -, o adolescente de Charleville já possui, como lembra Suzanne Bernard, um dogma, a vidência, e um método, o desregramento de todos os sentidos. (cf. Introduction. In: RIMBAUD, 1980, p. XXXIII). Além disso, a criação poética está associada ao conhecimento de si mesmo e do mundo. $\mathrm{O}$ ato criador constitui, portanto, um ato vital, enraizado na reorganização da realidade por meio da imaginação, das pulsões interiores e das sensações. A poética de Rimbaud sugere, como outras poéticas da modernidade, a inseparabilidade entre arte e vida. Mas fazer-se vidente é também um processo de renovação da linguagem. "As invenções do desconhecido exigem formas novas" (RIMBAUD, 1980, p.188), escreve o poeta, que se propõe a "encontrar uma língua" (p. 187) para exprimir "o novo: idéias e formas" (p. 188). A experiência da vidência está, portanto, associada à criação de uma linguagem nova, capaz de transmitir da maneira mais intacta possível as criações do Desconhecido.

A rejeição do passado se dá porque, para Rimbaud, o verdadeiro poeta, alimentado pelo desejo de chegar ao Desconhecido, busca inspecionar sua alma por meio de um método consciente e bem definido e ao fazê-lo necessita de meios de expressão adequados para expressar o inaudito, a "nova língua", que rejeita o discurso racional e lógico e desafia nossos hábitos de leitura conforme codificados pela tradição.

Depois de incluir na Carta outro salmo, o poema "Mes petites amoureuses", que o poeta considera "hors texte", Rimbaud retoma a discussão sobre a poesia e sua função. Chama atenção, nessa passagem, a predominância de verbos no futuro ou em tempos 
que remetem ao futuro. É o momento em que o poeta apresenta seu ideal de poesia vindoura e antecipa os princípios que regerão o fazer poético vindouro. Primeiramente o poeta é definido como um "ladrão de fogo". Como Prometeu, ele deverá encarregar-se de toda humanidade, mas de um modo particular, fazendo sentir, apalpar, escutar suas invenções (cf. RIMBAUD, 1980, p. 187). Assim comoLautréamont aventou a possibilidade de uma poesia coletiva, Rimbaud alude a uma língua universal, que fale a todos os homens: "Esta língua será de alma para alma, resumindo tudo, perfumes, sons, cores, pensamento tocando o pensamento e puxando" (RIMBAUD, 1980, p. 187). Notase, portanto, que a língua universal está fundamentada nas sensações e, como estas estão ancoradas no corpo, chega-se à universalidade e à materialidade. Além da criação da língua universal, o poeta tem outra missão importante: "definir a quantidade de desconhecido que se revela em seu tempo". O poeta é responsável pelo novo, é capaz de criar, por meio de seu poder imaginativo, um novo núcleo, um novo nó no universo. Esse nó é o poema, organização verbal única, que estabelece novas modalidades de relação entre as coisas. $\mathrm{O}$ verdadeiro poeta não reproduz a realidade, mas acrescenta a ela algo novo. Dois elementos importantes associados à modernidade estão presentes nessa idéia. A primeira delas diz respeito ao culto do novo como valor absoluto, que no limite vai estar condenado a ser superado. O segundo é a idéia do progresso no campo artístico: o poeta, diz Rimbaud, será um multiplicador de progresso, a poesia não ritmará a ação, estará avante. E avisa: "Esses poetas serão!". Ao pensar no poeta como um multiplicador de progresso, Rimbaud, como lembra Renato Poggioli (1997), parece tentar conciliar duas vanguardas, a de tradição sócio-política, que inspirou Saint-Simon e Fourier, que acreditavam no progresso das artes e concebiam o poeta como um guia para a humanidade, e a vanguarda estética do final do século, completamente arredia ao conceito de progresso e ao engajamento, fechada no esteticismo dos decadentes, na ambição metafísica de Mallarmé, ou na torre de marfim dos simbolistas. Comentando a Carta do vidente, afirma Poggioli:

Por um instante, as duas vanguardas parecem estar aliadas ou unidas, renovando assim a precedente tradição romântica estabelecida no decorrer das gerações encerradas entre as revoluções de 1830 e 1848 [...] Esta aliança sobreviveu na França até a primeira das modernas revistas literárias, intitulada significativamente La Revue independente. Esta revista, fundada em 1880, foi talvez o último órgão que reuniu fraternalmente os rebeldes da política e os rebeldes da arte, os representantes das opiniões avançadas nas esferas do pensamento social e 
artístico. Depois, logo houve o que poderíamos chamar de divórcio entre as duas vanguardas. (1997, p. 11-12).

Ao comentar o texto de Poggioli, Calinescu atenua a separação absoluta entre as duas vanguardas. No entanto, esse reencontro pleno entre a vanguarda estética e a vanguarda política só se fará presente novamente no início do século passado, com a militância política das vanguardas históricas. Para Rimbaud, o futuro já se projeta como continuidade e completude do presente. Evidentemente é preciso relativizar o conceito de progresso em Rimbaud. Não está presente em sua concepção de progresso a ideia de evolução, nem existe um juízo de valor. Para ele o progresso é, sobretudo, cumulativo. Cada poeta é responsável pela quantidade de desconhecido em seu tempo, pois o ato de criar o novo força as portas do conhecimento presente. Assim, os poetas do futuro, vivendo o presente do porvir, virão somar suas visões àquelas dos poetas do passado.

A aliança entre o presente e o futuro torna-se um tema relativamente frequente na produção poética de Rimbaud e se reveste das mais variadas roupagens poéticas. Uma das ocorrências mais significativas desse tema encontra-se no último poema das Illuminations, "Génie". Apesar da diversidade de interpretações que o poema suscita entre os estudiosos da obra de Rimbaud, é inegável que o Gênio de que trata o poema é o próprio poeta. Seu canto vem anunciar os tempos novos. No primeiro parágrafo do texto, o Gênio é apresentado em sua relação com o presente e com o futuro:

\footnotetext{
Ele é a afeição e o presente pois fez a casa aberta ao inverno espumoso e ao rumor do verão, ele que purificou as bebidas e os alimentos, ele que é o encanto dos lugares fugazes e a delícia sobreumana das estações. Ele é o afeto e o futuro, a força e o amor que nós, tesos nas iras e nos tédios, vemos passar no céu de tempestade e as bandeiras de êxtase (RIMBAUD, 1998, p. 301).
}

A condição do Gênio realiza-se na intersecção do presente e do futuro. Ele é o ídolo de uma nova era, o primeiro dos tempos novos, aquele que abre as portas para o que virá, antecipando o futuro no presente. Por isso o poeta, ao final do poema, convidanos a "convocá-lo e vê-lo", a "seguir suas vistas, seus sopros, seu corpo, seu dia" (p. 303). Definido inicialmente como a afeição presente e futura, o Gênio é também "a força e o amor" e Rimbaud celebra nele "a fecundidade do espírito" e a "imensidão do 
universo". Ele encarna a era moderna que vê a abolição das superstições, a migração dos povos e, enfim, o amor universal, "medida perfeita e reinventada" (p.301). Mas para que o presente torne-se sinal do futuro é preciso romper com certos preceitos ultrapassados. A voz do Gênio faz-se profética, pois é um convite a uma mudança de rumo, a um novo presente: "Afaste estas superstições, esses antigos corpos, as idades e comodidades. Foi esta época que soçobrou” (p. 301). O Gênio traz em seu próprio corpo "o estilhaçar da graça cruzada de violência nova”, pois o futuro só se instaurará por um ato de violência contra a tradição, contra a retórica desgastada, contra as limitações do ser. Como se pode notar, o tom entusiástico, a eloquência das imagens, a dialética da ruptura e a "religião" do futuro dão a "Génie" o tom de um manifesto cujos princípios e cuja retórica não estão muito distantes daqueles que adotarão as vanguardas de tendência futurista.

\section{REFERÊNCIAS}

\section{CALINESCU, M. Cinco caras}

de la modernidad. Traducción de María Teresa Beguiristain. Madrid: Tecnos, 1991.

COMPAGNON, A. Os Cinco paradoxos da modernidade. Tradução de Cleonice P. B. Mourão, Consuelo F. Santiado e Eunice D. Galéry. Belo Horizonte: UFMG, 2003. POGGIOLI, R. The Theory of Avant-Garde. Cambridge/London: Harvard University Press, 1997.

RIMBAUD, A. Oeuvres. Édition de Suzanne Bernard. Paris: Garnier, 1960.

Prosa poética. Tradução, prefácio e notas de Ivo Barroso. Rio de Janeiro: Topbooks, 1998.

RIMBAUD, A.; LAUTRÉAMONT; CORBIÈRE, T.; CROS, C. Oeuvres poétiques complètes. Paris: Robert Lafont, 1980. 